\title{
Streets: Freedom, Diaspora, and the Erotic in Head-On
}

Cinema, not as a second-order mirror held up to reflect what already exists, but as a form of representation ... is able to constitute us as new kinds of subjects, and thereby enable us to discover places from which to speak.

(Stuart Hall 1990, 236-37)

While not all films challenge traditional subject identities, Stuart Hall's idea of cinema as transformative constitutes the premise of a search for affirmative aesthetics that unveil the wilful positions that are born through film. However, these new positions are not always easy to hold, even within representation, as the previous chapter has shown: wilfulness may need to be masked in order not to be brought down. The performance of gender, both unescapable and uninhabitable according to Judith Butler, partly masks wilfulness, which thereby takes shape as micro-instances on screen. Through the analysis of Gegen die wand/Head-On (Fatih Akin 2004), this chapter builds on Butler's phrase that gender is 'uninhabitable' (1993), and that habitation of space is always anchored in time and thus context. Although the protagonist of the film may appear stuck in an inescapable spiral of performances of gender, her bodily habitation of the cinematic space suspends gender expectations. Bodies and spaces take forms that produce wilful claims and open up future possibilities for women to fully inhabit the streets. As Stuart Hall's words reflect, the affirmative

(C) The Author(s) 2020

M. Ceuterick, Affirmative Aesthetics and Wilful Women, https://doi.org/10.1007/978-3-030-37039-8_5 
aesthetic of the film is also the power of cinema: to de-territorialise the Western myth of the subject. Head-On constitutes the subject in its multiplicity, complexity, and relationality - as always liminal, always on the threshold of rather than fixed by categories.

I discovered Head-On when I was searching for films depicting mobile and empowered women. I remembered Auf der anderen seite/The Edge of Heaven (Akin 2007) because it left its mark on me several years ago. I was struck by the relatively easy movements of the German protagonist in The Edge of Heaven compared to the limited or relatively nonexistent mobility of her Turkish friend and that her ease and her ignorance of codes eventually result in her death in the streets of Istanbul. Like other films made by Akin, such as In the Fade (2017), Head-On seems to make a political statement on issues of gender, space, 'race', and mobility. Head-On particularly emphasises how gender, culture, and race as categories of identity affect the subject's habitation of space and the cinematic representations of spaces themselves. In the film, the characters' relations to streets and other so-called public spaces make reference to subjects constituted in gender and dynamics of exclusion. A micro-analysis of the film's formal constitution of spaces and bodies, however, reveals spaces and subject identities as processes, which are fluid and in constant transformation, rather than fixed into gender and racial categories.

Throughout Head-On, the desire of Sibel (the film's woman protagonist) to find a home, a place of belonging as a woman and a child of immigrants, haunts the film and Sibel's habitation of space. The film belongs to what Hamid Naficy (2001) calls 'accented cinema': films that integrate the double consciousness of the filmmaker within the film's narrative and aesthetic style, as characterised by the fragmentation, displacement, and tensions of living in between two cultures. Sibel comes from a conservative, patriarchal Muslim Turkish family living in Hamburg, Germany, and like Cahit, the male protagonist, she tries to commit suicide and ends up in a psychiatric hospital. When she meets Cahit and realises that he is Turkish, she pressures him to marry her so that she can leave her parents' house and be free to live as she pleases. Once married, Sibel moves into Cahit's apartment and appropriates the space by redecorating it. Although Sibel and Cahit both live separate (sexually liberated) lives, they become increasingly attached to one another. This attachment has disastrous consequences: out of jealousy, Cahit accidentally kills one of Sibel's former lovers, Niko. Sibel is forced to flee from the city after her brother learns of her unconventional lifestyle and threatens to kill her. Once in Istanbul, she replicates the freedom 
of movement that she acquired in Hamburg until, after a drunken night, a man rapes her in a bar and a group of men beat her up in the streets. The narrative then returns to Cahit, who has been released from prison and is searching for Sibel in Istanbul. When he finds her, Sibel has a daughter and a partner and lives in a modern luxurious apartment, in stark contrast to her previous life with Cahit. Although they both planned to travel together to Cahit's hometown in Turkey, the film ends with Sibel's last-minute decision to stay with her daughter and partner in Istanbul.

Sibel's habitation of diegetic spaces (such as streets), and how these take shape on screen give form to the difficulties of inhabiting gender or race, that is, categories of identity imposed on the subject. If Sibel struggles to fully inhabit space (both public and domestic) because of gender expectations, her cultural hybridity further complicates her sense of belonging to the city. Like the film's director, Fatih Akin, Sibel was born in Hamburg to Turkish parents. She lives in Germany but travels to Istanbul. As a descendent of Turkish migrant workers in Germany, Akin can be considered a diasporic filmmaker, and though it seems cliché to think of Istanbul as a place where the East meets the West, this duality is nonetheless at the core of Akin's films (Dimitris Eleftheriotis 2012, 133-34). Sibel and other characters in the film are profoundly and complexly marked by their ethnic and gender in-betweeness, which is demonstrated by the film's locations and soundtrack. From the very beginning of the film, both Cahit and Sibel are shown as cultural others through their performance of traditional gender norms. As subjects of a Turkish-German diaspora (see Hamid Naficy 2001), they neither belong to the Turkish culture nor to the German one. Cahit and Sibel both live 'with and through [cultural] difference', following Stuart Hall's analysis of diaspora (1990, 235). With regard to their Turkish- and German-ness, Cahit and Sibel are hybrid characters 'constantly producing and reproducing themselves anew, through transformation and difference' (Hall 1990, 235). The film itself adopts hybrid forms, mingling German and Turkish languages, Western and Oriental music, and locations in Germany (Hamburg) and Turkey (Istanbul).

As the film deplores the inescapability of gender and cultural codes, it creates what I call 'cracks' (using a Deleuzian vocabulary) in the diegetic punishment of characters who live outside of these codes. The formal representations of bodies and space crack open, break, or suspend the status quo apparent in the diegesis, at times only subtly or temporarily. As will be explored, the woman protagonist's search for the erotic and the visual 
abjection of 'whole bodies' through cuts, blood, and scars are filmic refusals to succumb to conventions, which open up the subject and spatial habitation as deeply liminal. This chapter unveils the film's making of space and bodies as processes in constant transformation. In particular, it focuses on how the woman protagonist wilfully inhabits the city, through walking, dancing, and establishing relations, in defiance of gender and cultural expectations.

Considering women who travel alone in Gender, Genre, and Identity in Women's Travel Writing, Kristi Siegel asks, 'What is at risk [when women travel] - a woman's safety or her morality? Is the amount of risk entirely real or, in part, magnified by its long social and medical history? Most importantly, what women are being warned and what kind of travel is being addressed?' (emphasis in original 2004, 69). Siegel's questions encapsulate the problematic power-geometries at play in women's habitation of public spaces on both a de facto and rhetorical level. As explored in the previous chapters, gender, sexuality, ethnicity, age, and other socioeconomic factors determine power relations, which in turn determine our habitation of space and the making of space itself (see Certeau 1984; Di Méo 2011; Lefebvre 1974; Massey 1994; McDowell 1999; Rieker and Ali 2008; Rose 1993; Spain 1992). It is in the affirmative representation of space and bodies that subjects appear as essentially liminal, in constant transformation.

\section{A Rewriting of Space-Time}

From the start of Head-on the focus on space as space-time is manifest within musical tableaux, which structure and interrupt the diegesis. Six scenes of a traditional Turkish orchestra punctuate the narrative with the Turkish-Romani piece 'Saniye'm'. On a representational level, the tableauxlike scenes stress major shifts in the characters' lives, and they divide the film into five parts that could be understood as the five stages of grief, as defined by Elizabeth Kübler-Ross (2005): denial (Sibel's and Cahit's refusal to live), anger (their extreme decisions), bargaining (daily life), depression (Sibel's perception of life in Istanbul as a sort of prison, and Cahit's actual imprisonment), and acceptance (Sibel's new life as a mother in Istanbul and Cahit's return to Mersin, where he was born). The characters' grief is mostly a grief of identity, the inability to inhabit an intercultural and gendered subject. The tableaux's colours and mise-en-scène give form to a circular yet open space-time. When Richard Dyer analyses non-representational signs (that 
he defines as 'colour, texture, movement, rhythm, melody, camerawork') in musicals, he writes that musical numbers can both reinforce and suggest 'an alternative to the narrative' (2002 [1992], 20; 28). While the tableaux reinforce the specific cultural hybridity of the film, they also imprint a tale-like dimension, placing the film outside of a definite time.

Head-On opens with Turkish-Romani clarinet player Selim Sesler and German-Turksish actress Idil Üner performing 'Saniye'm' with Idil Üner singing and standing in the middle of six seated men playing traditional instruments. A fixed camera films the performance in a medium-long shot that situates the orchestra on the 'Asian side' of the Bosphorus Strait, which divides the city of Istanbul. Meanwhile, the iconic Blue Mosque appears in the background on the 'European side' of the city (the side most-frequented by tourists) and gives this scene and the other muscial-interlude scenes a 'postcard' feel. The tableaux unfold with the stages of day, opening the film with sunrise and closing it with sunset (see Fig. 5.1). Although they appear fixed in a postcard-like space, microchanges within the tableaux and the unfolding day situate the film within both an atemporal and a specific space-time. On the one hand, the song's love tale and the very traditional and classical mise-en-scène-conveyed by the orchestra's long dresses and tuxedos and their immobility 'on stage'appear to suspend time and give a timeless dimension to the film. On the other hand, the outdoor location, in between the Asian and European continents, mirrors the protagonists' hybrid sociocultural identities and anchors the film in a specific space and time. This outdoor location and the modern texture of the image anchor the scenes in contemporary time, a time of modern, portable cameras polished image and sound.
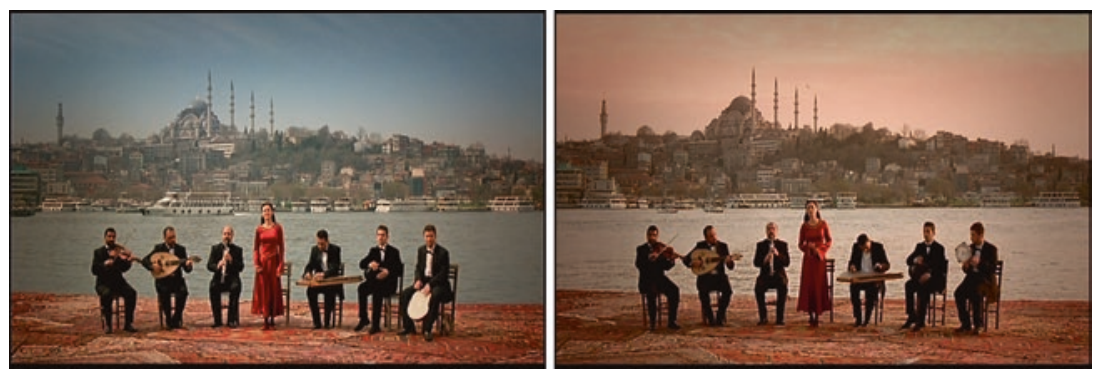

Fig. 5.1 Head-On: Chanting tableaux opening and closing the film 
Setting the performance in the course of one day emphasises the unstoppable circularity of time, and thereby the repeatability of tales of impossible love and the inescapability of social codes and expectations. The performance has a clear beginning and end also marked by codes: the film and performance begin with the first chair counting out the tempo and end with the orchestra taking a bow. Performances, live or recorded, are in itself acts that can be repeated, but with variations. Similarly, the film's narrative also appears as a timeless tale-a wilful woman who seeks liberation from a sociocultural jail, finds freedom through the erotic, and is imprisoned back into a timeless gendered role of a mother within the domestic sphere. The female protagonist partly imposes this role on herself, willingly-but this role is also contingent, one of many other possible alternatives or turns the diegesis could have taken. The enclosure of the film within the musical performance, itself enclosed within the passing of the day, gives form to both the inescapability and the variability of history, freedom, and power-geometries.

The tableaux artificially interrupt the fluidity of the narrative with their postcard dimension in a location absent from the narrative, and traditional music contrasting with the film's modern soundtrack. They emphasise the fictional construction process behind the film, one through which stories can be repeated, changed, or manipulated. If the tableaux mirror the performative and ineluctable dimension of heterosexual love stories and gender norms, the micro-changes within the tableaux themselves-the woman singer stands, sits, sings, or keeps silent-also mirror the ever-changing dimension of space and powergeometries. These micro-changes also allow for the possibility to recognise the multiplicities present within the real and to write on the map the real's stratifications and lines of flight. As this chapter will explore, micro-instances of affirmation appear through the (de-)organisation of cinematic spaces and bodies, the erotic, dance, abjection, and finally spaces of pause and transit.

\section{Freedom And the Erotic as Power}

Narratively, Head-On focuses on the difficulty of the woman protagonist, Sibel, to inhabit the city as freely as her male counterparts, to walk the streets of Hamburg and Istanbul day and night, and to become a modern flâneuse. In her book Wanderlust, Rebecca Solnit highlights how walking for pleasure began with modernity, when streets became 'clean, safe and 
illuminated places' (2001, 177). Yet urban space was, and still is, not safe for and accessible to everybody, as gender, race, age, socioeconomic background, and sexuality play an important role in determining who can access which parts of cities and at what time. In the time of the flaneur, women were commanded to be accompanied by men to "ensure their safety' (read: protect them from other men) or justify their presence in the public sphere, 'defined as the world of productive labour, political decision, government, education, the law and public service, [that] increasingly became exclusive to men' (Pollock 1988, 67-68). Women themselves were also divided according to ethnicity and social class. In her famous essay 'Modernity and the spaces of femininity', Griselda Pollock explains that while bourgeois women could not freely access public places such as masked balls and café concerts without damaging their 'feminine respectability', working women were identified as being outside of 'femininity' $(1988,78)$. Urbanisation, however, brought about the possibility for promiscuity, economic independence, and revolutionary ideas that undermined patriarchal authority (Wilson 2001, 73). Audre Lorde identifies promiscuity and the discovery of sexuality as a structure of resistance against patriarchy; the erotic is 'the power which rises from our deepest and nonrational knowledge', a 'deep and irreplaceable knowledge of [our] capacity for joy' $(1984,46 ; 48)$. Women's connection to the erotic-a resource that Western society has systematically oppressed, abused, and vilified-becomes 'a lens through which we scrutinize all aspects of our existence', which allows us 'not to settle for the convenient, the shoddy, the conventionally expected, nor the merely safe' (Lorde 1984, 48-49). In this first section of the chapter, I will consider how Sibel's connection to the erotic is a source of power against patriarchal domination that takes shape through the film's space.

In Head-On, the reclaiming of the erotic in particular figures as a position from which to speak, as a way of taking space, and as a method for making feminist spaces. As Sibel embraces the erotic, she is searching for freedom, the freedom to fully inhabit the streets and other 'public' spaces. Philosopher Elizabeth Grosz defines freedom as 'a process of self-making ... activities one undertakes that transform oneself and (a part of) the world' (Grosz 2010, 152). Sibel's actions, movement, and representation of herself act as liberation from the constraints that her family imposes on her, and, in Grosz's words, as an '[expansion of] knowledge production,... [and] the creation of a future unlike the present' $(2010,154)$. Grosz's definition of freedom is an affirmative one, not 'freedom from' but 'freedom to', which 
resonates with Braidotti's idea that freedom arises from the awareness of our limitations. For Grosz, the 'freedom to' is finding a space (albeit small) for innovation amidst present constraints or containment, at the level of both the individual and the species. Head-On figures as a rewriting of the present, as innovation, through the characters' actions and the cinematic making of diegetic spaces such as streets, bars, and houses.

Sibel appears in constant innovation, writing herself and the spaces she inhabits outside of gender and racial expectations. After a 'prologue' that focuses on Cahit's suicide attempt, we see a series of unattributable shots edited together: a white ceiling light, two different exit signs, alarm bells, a poster of an insect, and a doctor's plate, all of which locate the scene within a hospital where Cahit has been admitted. After the series of fastedited objects in close-up, the handheld camera stops on a young woman, Sibel, looking straight into the camera with a deep gaze and subtle smile (see Fig. 5.2). A reverse close-up then reveals the object of her gaze: Cahit, who is looking directly into the camera (and thus at her), and shortly after he looks away, he is visibly embarrassed by Sibel's gaze. Rather than a

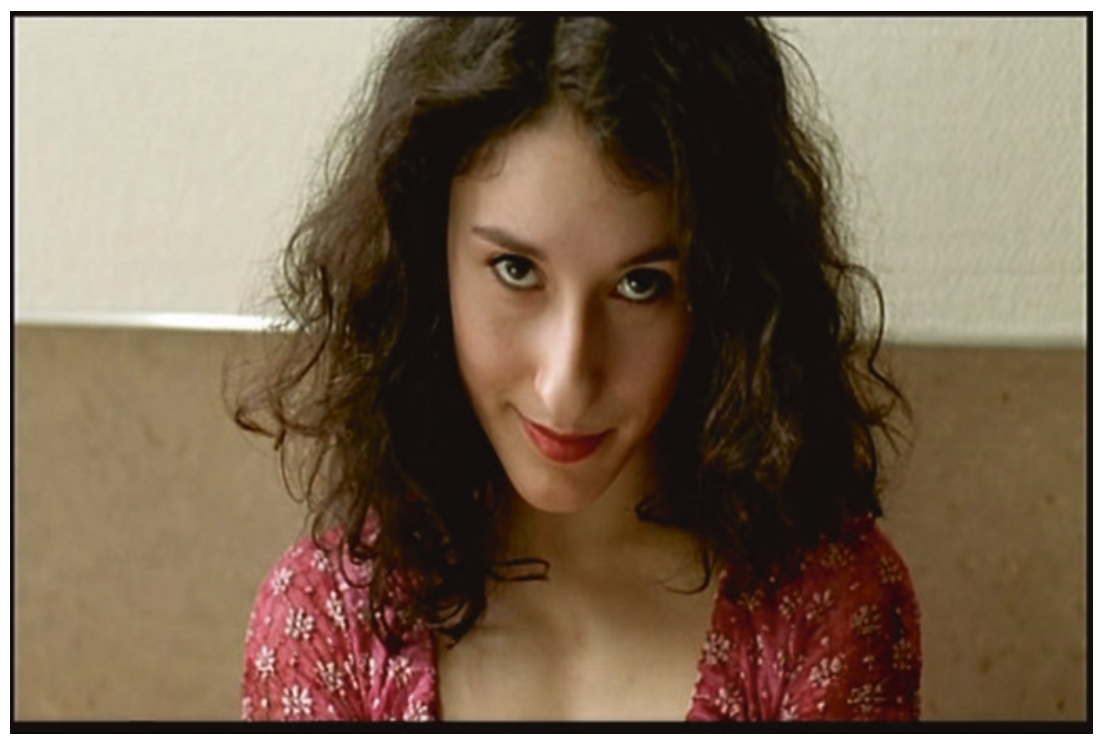

Fig. 5.2 Head-On: Sibel looking directly into the camera and at Cahit 
spectator to Sibel's performance, Cahit becomes her prey, and her exit door from an oppressive system. While Sibel's own suicide attempt did not liberate her from her father's and brother's control over her sexuality and mobility, she hopes that marrying Cahit could be a way to escape the domestic family space.

The centred close-up on Sibel as she looks directly at the camera introduces her as wilfully embodying the screen space. The framing of the characters gives shape to the power geometries existing between them and within the space they inhabit. When Sibel and Cahit later escape from the hospital, they go to a bar for a beer. There, when Sibel ignores one of Cahit's questions, the medium shot of Cahit becomes a close-up as he leans forward and repeats his question authoritatively. The cinematography expresses Cahit's attempt to physically assert his power over Sibel through his occupation of space. In response, Sibel, in a reverse medium shot, leans towards him in a close-up, thereby asserting her own spatial power over the male character. The affective power she has in their conversation and in the previous scene at the hospital merges the power of the erotic and a wilful habitation of space. As he responds to Cahit, 'I want to live, Cahit. To live and to dance and to fuck!', Sibel asserts her will of a 'freedom to', by 'putting her body in the way' of patriarchy (in the words of Sara Ahmed 2014, 163).

As the previous chapter has shown, one sometimes needs to dissimulate wilfulness in order not to be forced (Ahmed 2014, 139). From the start, the film constructs Sibel as a wilful women who refuses to be an object of the gaze and fully inhabits the cinematic space. Naturally, she plays different versions of herself depending upon who she interacts with; her performance varies based on whether she interacts with Cahit, her mother, or her father and brother. On the one hand, she performs a Western image of 'femininity' by wearing shirts that display her cleavage and keeping her long hair untied; on the other hand, when her family comes to visit her at the hospital, she ties her hair back, removes her makeup, and wears loose clothes (see Fig. 5.3). In this scene, the forms of her family's bodies and the multitude of objects in the foreground and background overwhelmingly fill up and fragment the cinematic space. A topoanalysis reveals how traditions and gender expectations (embodied by Sibel's family) impose their power on the woman protagonist and crush her wilfulness. With her family, Sibel reproduces a particular 'compulsory repetition' of gender norms (Butler 1993, 21-22), which they require of her. However, Sibel's pink cardigan and her white t-shirt with an orangecoloured figure with raised arms on the front (as if expressing fight or 


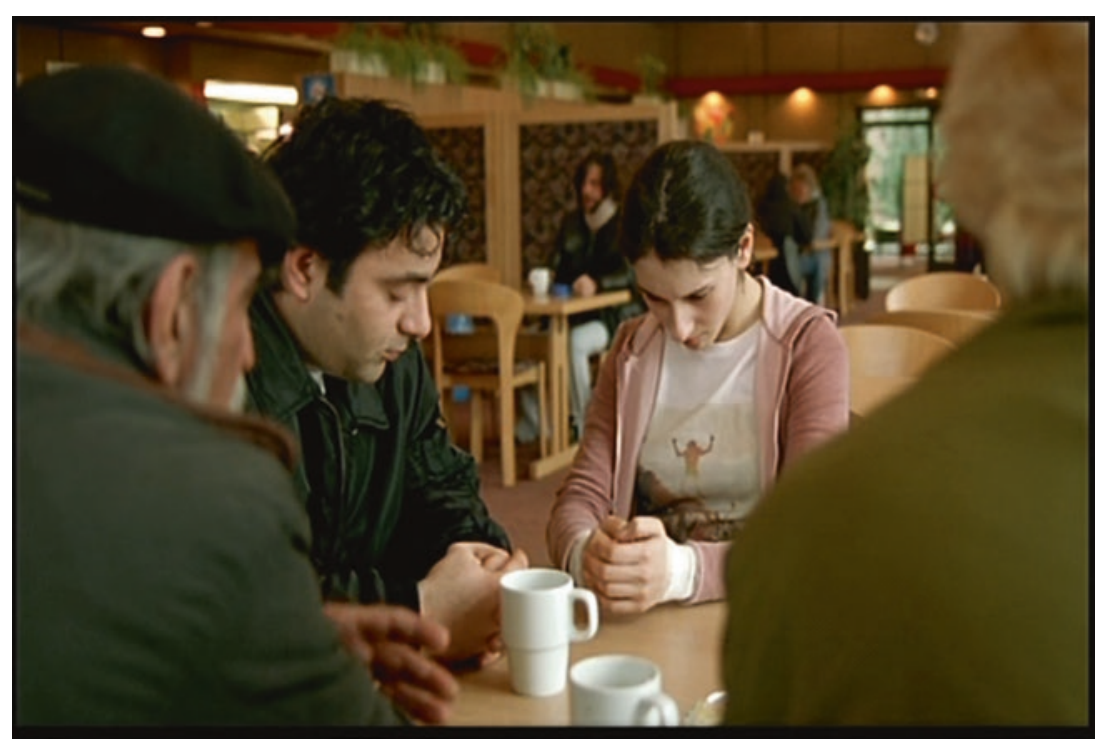

Fig. 5.3 Head-On: Sibel being submissive in front of her father and brother

victory), contrast with her family's darker and sober garments and visually give shape to a micro-instance of resistance. Once the male members of her family have departed, she removes her submissive mask as she pushes her chair back to sit at ease: she crosses her legs, unties her hair, and lights a cigarette. While Sibel's second embodiment appears more in touch with her body and wilfulness to take up space, it cannot but remain what Butler calls 'performative' of another type of 'femininity', an unconscious reiteration of gender norms. Whereas Butler asserts that there is no way out of gender, the mise-en-scène of Sibel's body and the cinematic space indicate otherwise throughout the film, whether through microinstances or the subversive queer and punk lifestyles of the characters.

By marrying Cahit and thus escaping the strict patriarchal scrutiny of her brother and father, Sibel embraces the erotic as a view of the world, a lifestyle. If the privilege of casual sexual relationships is reserved for men, as Sibel will learn, she establishes a connection to her body, a power to feel and live truly as she pleases. Marriage becomes a gateway to the sexual (which a conversation between Sibel and her female cousins, who ask about her sexual life with Cahit, illustrates); but paradoxically, Sibel finds her sexuality outside 
of marriage. The erotic works as a subversion, an innovation, and an opening to a possible future beyond conventions. Sibel and Cahit are married in a traditional Turkish wedding, but immediately afterward Cahit throws Sibel out of his filthy apartment when she asks about his deceased exwife. Sibel, wearing her wedding dress, goes to a bar to have a drink by herself and then seduces the bartender. Her encounter with the erotic manifests in her habitation of space and her masquerade of gender. Sibel seduces the bartender in an indirect manner, because of an internalised form of 'femininity' that plays with false timidity and the pretense of submissiveness as she waits for him to 'do the last move'. Her indirectness is also necessary because she lacks a space of her own (like Jeanne and Marie in Messidor) and thus has to wait for him to invite her to sleep at his place. At no point in the film does Sibel have access to a private space of her own, yet she builds transitional 'homes' through the erotic, 'a freedom to', and a 'lived body' through which she inhabits public spaces such as bars.

The connection to the erotic and Sibel's conversion into a lived body happens at an aesthetic level through the cinematic construction of bodies and spaces. The cinematic space of the bar sequence gives shape to the social and gendered dynamics of Sibel's encounter with the bartender and to Sibel's free, wilful body. On the one hand, the counter of the bar cuts the medium long shot horizontally and places Sibel on the 'demanding' side of the bar-thus indicating the bartender's position of power since he can choose to attend to her demands or not (see Fig. 5.4). On the other hand, Sibel is on the outside of the bar; she sits in an open environment free of objects (and is visually free to leave if she wants to), while the counter and numerous bottles and objects spatially enclose the bartender. While the editing of the sequence establishes the conversation and game
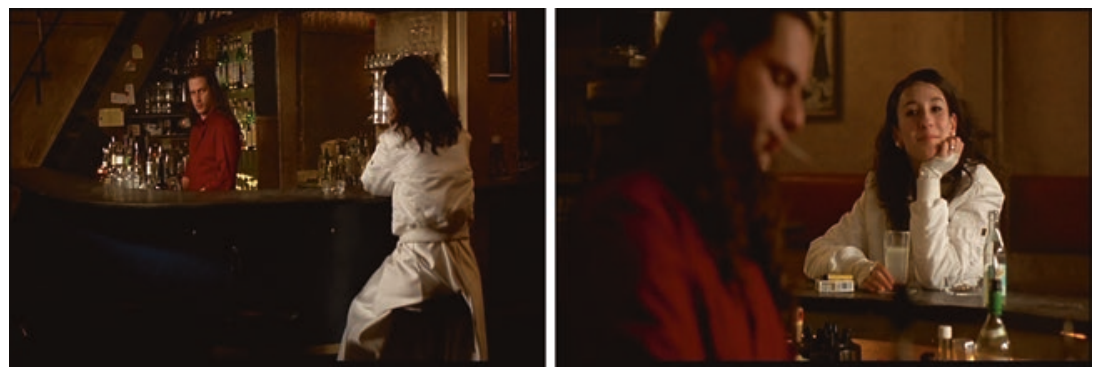

Fig. 5.4 Head-On: Fluid dynamics of power in the cinematic space 
of seduction through a classical shot/reverse-shot montage, a microanalysis of the editing and cinematography reveals more complex power dynamics. The camera's angle, at the same height as the characters, and its deep-space shots connect the two characters socially and spatially. However, the counter that separates the characters, and the bartender's often blurred appearance in contrast with Sibel's invariable sharp appearance, attribute a different degree of power to the characters. The longer takes showing Sibel as opposed to the short takes showing the bartender when he speaks (which sometimes even shift focus mid-sentence) narratively position Sibel as the main character and the one in power. Moreover, when the two characters appear together in the frame, the sharp focus on Sibel as opposed to the blur conferred to the bartender emphasises her as the subject of the gaze and him as the object. This contrast also gives Sibel's figure an embodied shape that is connected to a newly found freedom to fullyunashamedly-inhabit public spaces. A topoanalysis of this scene considers how the cinematic framing of objects and bodies gives affirmative forms to Sibel's habitation of the diegetic space. Sibel's connection to the erotic aesthetically transforms the power-geometries at play within social spaces: not as a product of Sibel's will but rather, as Lorde suggests, a deep sensory knowledge that has the power to subvert patriarchal domination and gender expectations.

When Sibel walks in the street the next morning after spending the night with the bartender, her bodily habitation of the cinematic space is again affirmative. The mise-en-scene and cinematography of the scene embody the wilfulness 'not to settle for the convenient' (in Lorde's words, describing the erotic, 1984, 48-49); it is both an individual wilfulness and that of a generational sociocultural group of women. The well-lit, slow-motion tracking shot of Sibel places her in the middle of the frame and grounds her in an environment that she now happily and fully inhabits. When Sibel crosses the street, the camera films her with a deep focus in a long establishing shot; her body stands in parallel with other vertical objects such as houses, doors, and windows, as she walks across the frame diagonally towards a camera tracking backwards (see Fig. 5.5). Rather than enclosing her, the objects and the lines they create in combination with Sibel's body and the line of her walking direction create what Barthes calls a line of flight' (1980), which opens the space onto both the foreground (through the camera tracking backwards) and the background (behind Sibel). Sibel's possession of the erotic gives form to her wilful habitation of the screen and 


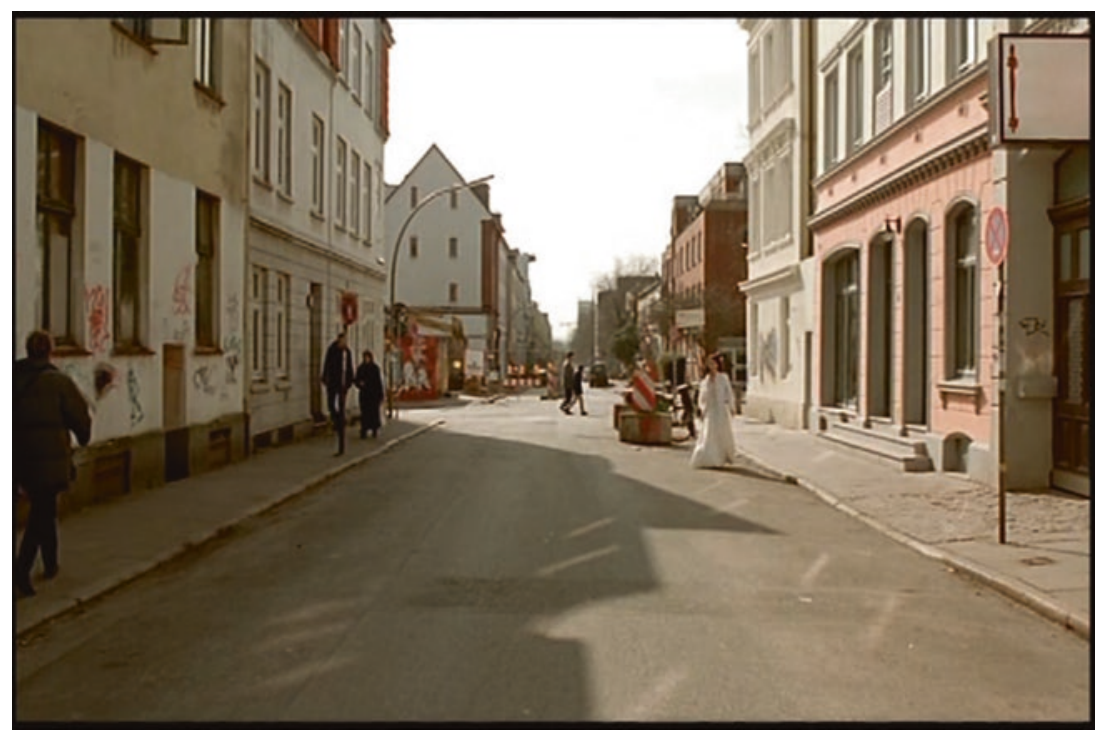

Fig. 5.5 Head-On: Sibel walking in the street

the diegetic environment; the open frame asserts her right to be there as any other body on screen.

\section{DANCE AND DiASPORA}

Sibel's full habitation of the screen and of the public space especially manifests through three dancing scenes, which punctuate the film and encapsulate the complexity of wilfulness, space, and subject identity. The difference of narrative outcomes between the scenes emphasises a cultural and gendered difference in sexual freedom. In one way or another, some elements of the scenes condemn Sibel's free sexuality. After the first dance scene in a German danceclub in Hamburg, Cahit destroys his apartment in a fit of jealousy when Sibel leaves to have sex with someone else (although Sibel and Cahit were never involved in a romantic relationship despite being married, and Cahit's own casual sex is never questioned in the film). As we will see, the aesthetic of the scene also negatively portrays Sibel's sexualised dancing style, with a fixed and distant camera that focuses as much on Sibel dancing in the middle of the frame as on Cahit unhappily watching 
her from afar. After the second dancing scene, Cahit is beaten up for attempting to 'rescue' Sibel from a Turkish man harassing her. And after the third dancing scene, Sibel is raped in a bar in Istanbul. Aesthetically, however, dancing in each of these scenes seems to be an act of freedom, which takes erotic, abject, and intercultural forms.

Sibel's first dance is a celebration of the erotic, a celebration of the freedom to 'dance, live, and fuck' (in Sibel's own expression), take control over her body, and inhabit a 'lived body'. As she is coming back from her first day at work with Maren (Cahit's lover), she shows Cahit her new bellybutton piercing (just like Maren) and tells him that she is also going to get a tattoo in the small of the back, the same spot where Maren has a tattoo. For Sibel, both the piercing and the tattoo represent erotic power. In contrast with her sober clothing she wears when she meets her family, Sibel embodies a sort of 'feminine' eroticism when she goes out by wearing a shirt that shows her a cleavage; she also fixes her hair and wears makeup on her eyes and lips. Whereas all of the other women in the (Western) nightclub wear jeans and t-shirts, Sibel wears boots with short shorts and a cardigan buttoned only at the middle of her torso, revealing both her cleavage and her new belly-button piercing, which Sibel had previously mentioned she wanted to 'show off'. The scene in the nightclub encapsulates the contradictory nature of gender, its compulsory performative (yet largely unconscious) repetitions of gender norms and its 'radical uninhabitability' (Butler 1993, 25).

Insofar as heterosexual gender norms produce impossible ideals, heterosexuality can be said to operate through the production of hyperbolic versions of 'man' and 'woman'. For the most part these are compulsory performances, ones which none of us choose, but which each of us is forced to negotiate. (Bulter 1993, 26)

If it could be said that in this scene Sibel performs a hyperbolic form of woman, her dancing is also a form of reaching out for the body and of letting go of control, while-maybe paradoxically so-gaining control. Through dancing, Sibel searches for the freedom (and the power) that the erotic promises. Maren's piercing and tattoo that Sibel appropriates are ways for her to own her body - through a German punk style rather than traditional 'feminine' attributes - ways denied to her by the patriarchs of her family.

Writing about nineteenth-century Paris, Elizabeth Wilson describes the city as an environment 'where women are able to gain freedoms-even if the price of this is their over-sexualisation and their participation in what 
is often a voyeuristic spectacle': '[cities] are spaces for face to face contact of amazing variety and richness. They are spectacle-and what is wrong with that?' $(1991,56 ; 158)$. In the nightclub, Sibel embodies an erotic spectacle from which she does not shy away. She dances in the middle of fixed medium shots looking straight into the camera (see Fig. 5.6). In a partial reverse shot, a handheld tracking camera comes to a close-up of Cahit, who looks steadily at Sibel. The change between fixed and handheld cameras imposes a distance in watching Sibel, while emphasising Cahit's discontent. If Cahit appears as a (jealous) spectator of Sibel's performance, Sibel rewrites herself while dancing and redefines what a 'feminine identity' means. Dance becomes 'a sexual ritual, a form of self-expression ... and a way of speaking through the body', in Angela McRobbie's words in her essay on dance narratives (1990, 195). In the previous scene, when she dances in the kitchen while Cahit prepares dinner, Sibel looks at her piercing in the mirror and says that she wants to go out and 'show it off', to which Cahit replies, 'Yes, I want to show you off too'. While Cahit's sentence positions Sibel as his possession, Sibel uses

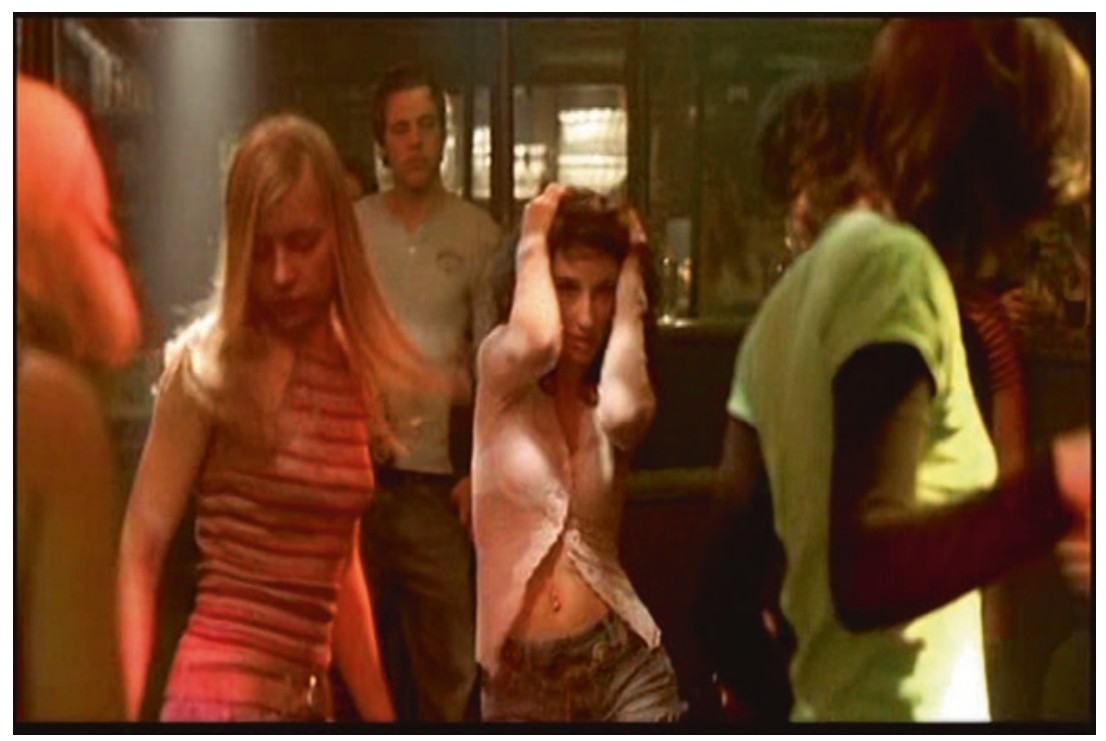

Fig. 5.6 Head-On: Sibel performing masquerade while dancing in a nightclub 
dance to make her body her own possession, though it also engages the gaze of others. Sibel herself would not be the object of the gaze-her piercing would be the object and act as a sign of her eroticism-and her body lives to the rhythm of music rather than rules of gender.

Dancing at once appears as an act of freedom, an expression of Sibel's individual subjectivity, and an act that makes space. The three dance scenes in the film de-territorialise the categories of gender and 'race' by encapsulating contradictions, subjects, and spaces as processes that constantly remake themselves. These dance scenes encapsulate the cultural hybridity of the film, present in the diegesis as well as in the mise-en-scène, music, and geographical locations. In the film, 'Western' or 'Eastern' elements merge indistinguishably; for example, a hybrid version of 'The temple of love' (a song originally sung by The Sisters of Mercy re-mixed with the voice of Israeli singer Ofra Haza) plays throughout the first dancing scene (both in the kitchen and louder in the nightclub). When Sibel leaves with a young blond man to 'get laid' (in her words), a traditional Turkish chord resonates, superimposed with the music, as if announcing a cultural incompatibility to her free sexuality (an incompatibility that is not only cultural but rather pervasively sexist, as will be explained later). Gender, 'race', and cultural customs also figure as uninhabitable, which becomes especially apparent in the second dance scene in a Turkish nightclub in Hamburg, when a man brutally interrupts Sibel and Cahit as they dance. The close-up of the man placing his body between Sibel and the camera visually interrupts the image and breaks the movement of the frame, which was moving in rhythm with the characters.

The mise-en-scène and cinematography of these two dance scenes both nourish and contradict the diegesis. While the first scene exoticised Sibel and kept her performance at a distance, her erotic power allowed her to exert her sexuality freely, though her sexuality is diegetically punished later in the film. In this sense, the aesthetic of the scene foretells future events of the diegesis and gives shape to the uninhabitability of gender. Similarly, in the second scene, the physical interruption of the characters' dance manifests visually as an interruption of harmony, a denial of the characters' ability to belong to a space. This denial is cultural, because of the characters' hybridity: they do not belong to any particular culture. Rather than being fixed in place (in the film's case, Germany or Turkey), culture is, in the words of Arjun Appadurai, 'an aspect of practice, of social life' that is not static and exists in its 'differences from something else' $(2002,45)$. The characters' hybrid German-ness and Turkish-ness is also apparent in 
the aesthetic of the second dance scene. The sudden changes and dynamics in the cinematography give form to sociocultural difference, the impossibility to get along with the idea of a cultural fixity: First, the transition from moving in rhythm to static close-ups of the unwanted male body when the man interrupts Sibel and Cahit, and then second, the fixed filming in high angle of the Cahit's ensuing beating. The interruption of the man is also an unwanted sexualisation and objectification of Sibel, reinforced by their dialogue. 'What do you want?', she asks. 'You', the man replies, followed by Cahit's 'That's my wife'. Sibel is here denied the ownership of her body and her sexuality; she is rendered as a gendered body and is denied the opportunity to live through the power of the erotic. The characters' inability to fully inhabit space on screen without being interrupted and replaced within a fixed frame, amounts to the inability to inhabit 'race' and gender as subject identities.

The third dance scene gives form to the subject as deeply liminal: always in constant transformation and on a threshold rather than fixed by mediated and cultural categories (such as race, gender, or sexuality). Stuart Hall writes that identity is a 'production, which is never complete, always in process, and always constituted within, not outside, representation' (1990, 222). Through the representation of Sibel and her habitation of space, the film places emphasis on the subject as a process, a body that lives through affects rather than gender, sex, or race. If multiple characters and events of the diegesis attempt to place her on a gender-coded path, the film's aesthetic and cinematic spaces give shape to Sibel's search for the erotic as a way to find freedom, embrace an uncomplete identity, and live outside of conventions. As the next section will explore in more detail, the uninhabitability of subject identities such as race and gender takes form on screen as abjection. After her family blames Sibel for bringing shame onto them through her liberated sexuality and Cahit's murder of Niko, she flees to Istanbul. Her life in Istanbul parallels Cahit's 'messy' life, demonstrated in the very first sequence of the film when he drives his car into a wall. By wandering in the streets at night dressed in black, with dark makeup, short hair, and baggy pants, and through her use of drugs and alcohol, Sibel wilfully disorganises her body and the codes that constitute her as 'feminine'. Sibel's 'cross-dressing' can be described as a way to negotiate gender norms, "[reiterating] a gendered idealisation and its radical uninhabitability' (see Butler 1993, 25). Sibel's presence in 'the interstices of the city' (in the words of Elizabeth Wilson 1991, 8) appears as a punk resistance to a capitalist world, which her cousin Selma embodies (with her 'work, sleep, work' routine that Sibel despises), and to a world in which women are not accommodated in public spaces. 
In the third dancing sequence that closes Sibel's punk life, she drinks and dances frantically in a bar in Istanbul to the point of collapse. While Sibel drinks and dances, the song 'I Feel You' by Depeche Mode plays, loudly and extra-diegetically, indicating Sibel's own self-destructiveness and anticipating the ultimate trajectory of her life ('I Feel You' also plays when Cahit drives his car into a wall at the beginning of the film). The lyrics of the song correlate with the diegesis of the film, in its suggested replacement of religion (the Muslim religion of Sibel's family) with sex and drugs ('you take me to and lead me through oblivion'). As Sibel drinks and whirls around, the handheld camera follows her movement in close-up, making a constant effort to reframe her in the middle, and even 'loses' her for a moment. The editing of the scene, through multiple cuts and dissolves of short takes of Sibel in close-up, condense the passing time while giving form to Sibel's wilful liminal subject. If the camera's framing of Sibel obeys the cinematic narrative conventions of keeping the main character in the frame - filmically integral to social norms-the disjointed editing gives shape to a resistance to integrate a normative frame of

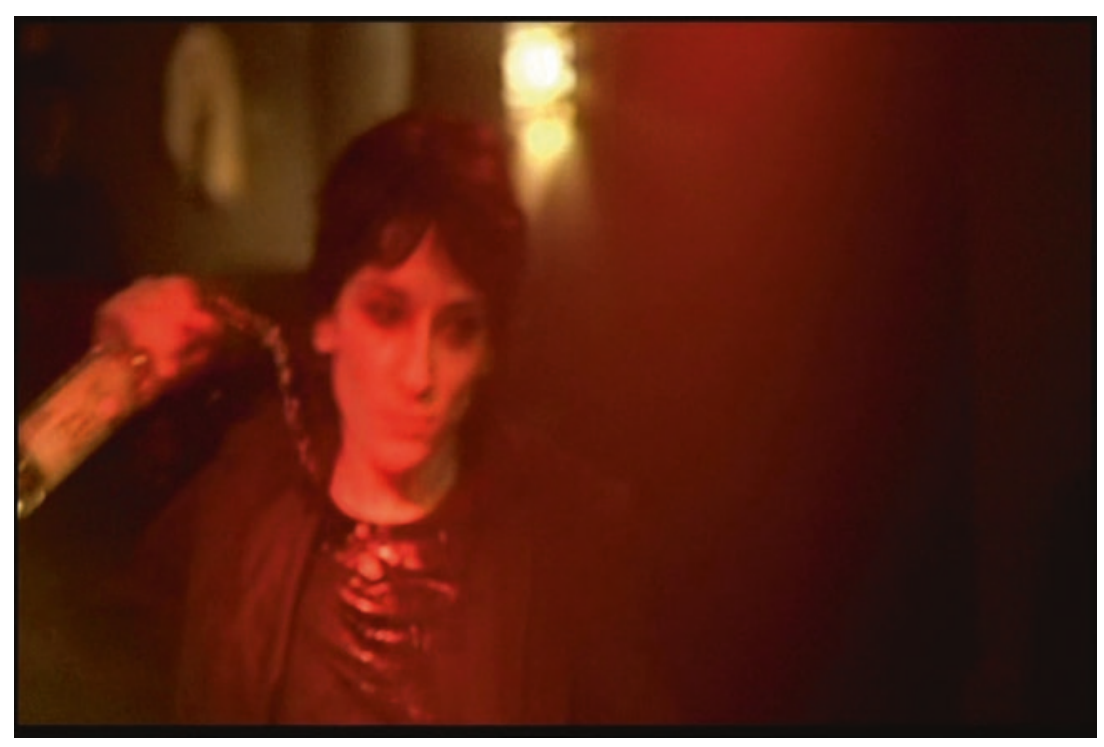

Fig. 5.7 Head-On: Sibel drinks and dances until she falls to the ground, unconscious 
identity. The blur of images and loud colours invade the frame and merge with Sibel's body. The aesthetic of this scene formally expresses Sibel's drunkenness (see Fig. 5.7) and participates in a de-territorialisation of the idea of a stable subject identity.

In the third dancing scene, the cinematic space embodies Sibel's resistance to how she has previously been contained, or replaced, in a gendered, sexualised, and racialised identity. The blurring of images and loud colours create a dream-like space, which Sibel angrily inhabits, putting her body in the way of other people's dancing. The protagonist is depicted as a body that has been affected by her habitation of bars (for example, by the man in Hamburg who invaded her space and sexualised her in the second dancing scene), and as a body who affects others (as seen through the reactions of people around her, who push her when she gets in their way and form a circle around her when she collapses). Dark yellow, orange, and red colours seem to merge the tones of the two previous dance scenes, thus visually embodying Sibel's freedom to 'dance, live and fuck' and ability to replace her gendered, sexualised body with a non-gendered, asexual body (in this precise scene). As Senta Siewert writes about this scene, 'just as the consumption of energetic and hallucinogenic drugs brings one into a non-space, a space outside the body, dancing can evoke a delocalization of the body that suspends normal affective relationships and perception of the self' $(2008,204)$. The filmic space gives shape to an affective-punkinnovation, the forming of a wilful and liminal subject. Her invasive and angry habitation of the bar provokes unwanted interruption of other people's private space, which appears as a destruction of norms and normal affective relationships. For José Esteban Muñoz, queer and punk performances manifest as a materialisation of possibilities and generate 'a utopia... [as] a time and a place that is not there yet' $(2009,99-100)$. In this view, Sibel's punk and queer habitation of the space-time of this scene opens up a utopia, aesthetically pointing out to 'something missing in the here and now' (in Ernst Bloch and Theodor W. Adorno's words, qtd. in Muñoz 2009, 99). It creates an affirmative opening into the capitalist and sexist structures of society that delineate subject identities and the habitation of space. The cinematography and mise-en-scène of the three dancing scenes give shape to the subject as an ever-incomplete process. While Sibel's rape following this third and last dance scene is a physical destruction of her body and erotic power, Sibel's queerness and the punk aesthetic of the dance scene are inherently affirmative forms in their wilfulness 
to suspend the myth of the subject as immutably delineated by gender, race, and sexuality.

\section{Punk and Abjection as Affirmative Forms}

Like dance, abjection becomes a wilful form, a resistance to the gendering and racialisation of the self. Sibel's punk resistance verges on the abject, both as a fascination and fear for the destruction of the subject-the subject as coded by patriarchal and racial laws. For Julia Kristeva, the abject is the unassimilable: what cannot be assimilated by the 'acceptable', the thinkable (the socially accepted self); abjection is 'a mix of judgment and affect, condemnation and effusion, signs and pulsions' (Kristeva 1980, 9; 17, translation mine). As the characters reject subjectification according to gendered, racialised norms, they embrace what is considered abject. This abjection of the self takes the form of blood in the film, and demarcates the fall of dichotomic and arbitrary boundaries between inside/outside of the body, the self/the other (see Kristeva 1980, 15). By looking at the forms of the abject in the film, we actually look at the forms that displacement takes. Sibel and Cahit's relation to blood, or to the sexual, is a form of internalisation of the abject, of being other, and of not finding space in a place that divides because it is totalising. For Kristeva, the perception of the self as abject is common for people in exile, as it questions the space which one occupies (or can occupy) $(1980,15)$. Living in a country where one is seen as 'other' and the uninhabitability of gender and racial identities take abject and affirmative forms on screen. Blood manifests as an erotic force, which is, in Lorde's words, 'self-affirming in the face of a racist, patriarchal, and anti-erotic society' $(1984,50)$.

Both Sibel and Cahit's intercultural situation and their refusal or inability to inhabit idealised gendered identities take the shape of self-abjection: bringing their selves to abjection by acts of self-destruction, or by letting others destroy them. The abject in the film figures at once as a rejection of norms, a symptom of not belonging (neither to the German nor to the Turkish community), a transgression, and a punishment for transgressing. While Cahit drives into a wall, beats people up or is beaten up, destroys his own apartment, has sado-masochistic sex, abuses drugs, smashes glasses with his bare hands, and dances with blood running down his arms, Sibel cuts her veins open three times in the film, takes drugs, gets 
drunk, and fights until the point of unconsciousness. Psychoanalytically, we can regard the characters as finding affective refuge in abjection, in response to being made 'other'. The abject manifests as a restitution of the body outside of the social codes, determining what is acceptable and unacceptable.

The emphasis the film places on blood, conventionally regarded as abject, as Kristeva underlines, amounts to a suspension of the coded gendered and racialised body, a refusal to exist within these codes, and a recognition of the subject as always being on a threshold, always liminal. Blood also symbolises the boundary between the inside and the outside of the body. Sibel's taped wrists indicate that she cut her veins open, so that, as she admits to her mother, her brother and father would 'leave her alone'. When she cuts her veins open again, the camera films the action in a medium shot while blood dramatically spurts out of Sibel's arm into Cahit's face, which spurs the other customers in the bar to flee. Narratively, this gesture is designed to force Cahit to marry her, and is a result of not being understood (as Sibel says to Cahit, 'You don't understand shit'), of not being able to live her youth as she pleases ('live, dance, and fuck, and not just with one guy', as she says to Cahit). Formally, however, blood becomes an internal fluid that 'reassures the self' $(1980,65)$; it gives shape to a body of flesh that is, on Cahit and everything around them, is a trace of Sibel, a stain that remains while it exits her body as a rejection of her own self. This rejection is a result of the profound inability to exist within gendered, racial and set cultural codes.

Cahit smashes two glasses with his bare hands, creating a bloodbathalso a result of 'not being understood', as he himself states. His subsequent frenetic dancing to Turkish music while blood runs down his arms, however, appears as an acceptance of his 'otherness' within a German context.

After a group of Turkish men beats Cahit up until he bleeds. When the fight is over, he says to Sibel 'Fucking Turks'. Sibel replies, 'What? But you are one of them'. This opposition between them and us manifests through language, as Cahit cannot speak Turkish, and his statement shows that he considers himself German. Others, however, do not see him that way. The doctor who sees Cahit after his attempted suicide comments on his 'exotic' Turkish name and compares it to 'our' German names, thus positioning Cahit as other. When Cahit and Sibel pay a visit to her family, he says he hates 'all this Turkish crap'. Cahit has internalised racism, and reproduces, through his violent behaviour and selfabjection, the subject identity given by the injunction 'you-other'. 
In another occasion, Cahit smashes two glasses with his bare hands... his arms, however, appears as an acceptance of his 'otherness' with a German context; the singer welcomes him on stage in spite of his bloody appearance. Cahit's 'bloody dance' unites the self-other distinction as a movement that embraces the abject. This time Cahit expresses abjection not through violence but instead through dance, as an erotic freedom to express oneself through the body. This is confirmed by the singer, who does not recognise Cahit's interior fluid as abject but welcomes him on stage. One reading of Cahit's and Sibel's relation to the abject would be to consider them 'bodies without organs', in Deleuze and Guattari's term (1980): their actions disorganise the body and the significances and hierarchies imposed on it by experimenting, moving, and dismantle the 'unity' of the subject through self-destructions (Deleuze and Guattari 1980, 197-98). While disorganising the body amounts to dismantling the strata of significances and subjectification that organise subjects within a majoritarian reality of dominations and exclusions, the abject is what remains of the body after it has been codified and ordered according to a particular context (see also Grosz 1994, 192-93). The aesthetic embrace of abjection is affirmative insofar as it participates in constituting the subject as essentially liminal, always in movement, on thresholds.

Several times in the film, Sibel makes herself or is made abject, as a punishment for her transgressions of gender, racial, and cultural codes. Just as in Vendredi Soir, the film's narrative and aesthetic constantly oscillate between Sibel's erotic freedom and her confinement within gendered and sociocultural codes. The first climax of the film unfolds from Sibel's empowered habitation of social spaces and the patriarchal and sexist repercussions. After making it clear to Niko that their sexual encounter was a 'one-off', Sibel goes by herself to an entertainment park. The movements of the camera and its long medium shots in slow motion, filled with colourful lights, position Sibel as fully inhabiting the screen space (see Fig. 5.8), similarly to when she walked the streets in her wedding gown after her night with the bartender. The camera follows her body's movement in the roller coaster and portrays Sibel's body as living through sensations rather than gender. Meanwhile, in the bar where the characters usually go, Niko goads Cahit about Sibel's 'whoring around' in a long static, fragmented, and obstructed shot (see Fig. 5.8). While the scenes in the entertainment park give shape to Sibel's ability to move around freely and control her own body and sexuality, the aesthetic of the parallel scene between Niko and Cahit hints at punishment for her transgressions.

Compared to Sibel's fluid and unobstructed habitation of the cinematic space, the cinematography, dialogue, and mise-en-scène of this dark scene 

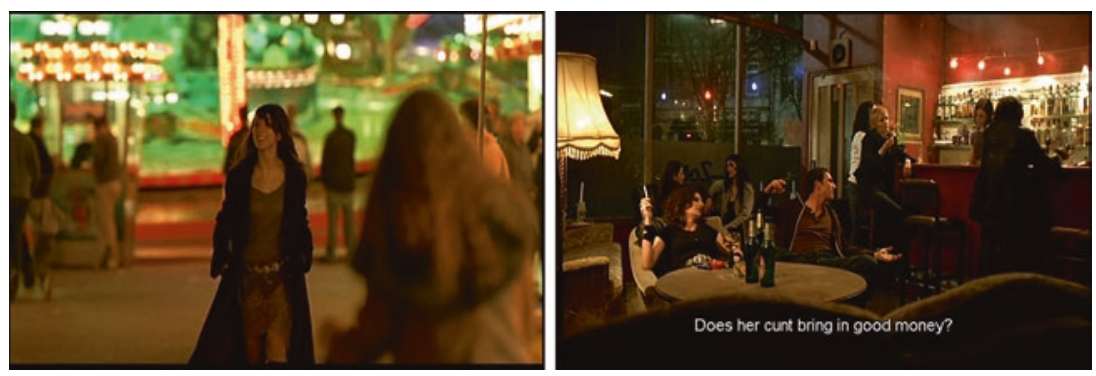

Fig. 5.8 Head-On: Parallel editing of Sibel enjoying the city and being confined in gender expectations

between Niko and Cahit attempt to return Sibel to a socially acceptable position. As Niko provokes Cahit through violent and racist comments, Cahit smashes a glass of beer on Niko's head, which ultimately causes his death. If Cahit goes to prison for his crime, Sibel is the one who is socially condemned for it and held as a 'dangerous woman' for her liberated sexuality. A dark musical phrase begins when her family realises what has happened. Both they and the media reporting on the event-through an article titled 'Jealousy killing' and a picture of the newlywed coupleblame Sibel for Cahit's violent outburst. Left without a place to call home, Sibel is forced to take refuge with Cahit's friend, Seref, who also blames her for what happened: 'Can't you see what you've done to him? You've ruined his life!' While Cahit's own 'extramarital' sexual life is never questioned, Seref's rebuke reinstates the persistent gendered dichotomy that defines women 'in terms of their sexuality in a way that most men [are] not' (Wilson 2001, 137). While Akin's film at times suggests the cultural nature of the double standards that allow men casual sexual relationships and refuse the same privilege to women (through the difference of outcomes of the three dancing scenes, for example), it also emphasises the pervasiveness and ubiquitousness of sexism: both Niko, a non-Muslim German, and the German media see Sibel's attitude about sex as a problem.

The lyrics of Wendy Rene's soul song 'After laughter comes tears', which plays throughout the sequence, from Sibel alone in the entertainment park to Cahit killing Niko, echo Sibel's predicament. The nondiegetic song seems to sarcastically comment on Sibel's wilful behaviour. As if it was diegetic, the music stops suddenly when Sibel, back at home, opens the compact-disc player and puts on an album by Turkish musician 
Agir Roman. The cross-cultural dimension of the soundtrack encapsulates Sibel's self-abjection, as she looks at herself in the mirror, crying, and cuts her wrist open again. The extreme close-ups of the razor blade dripping with blood give shape to what cannot be assimilated: the judgement and affect of her culturally hybrid situation. A lengthy shot in extreme closeup then focuses on the needle with which the doctor sews her wrist up. The needle leaves a trace on her arm-the trace of not belonging. This uncomfortable close-up gives an affective form to the abjected body, both a body that is refused a space and a body that is never complete and always in the making (although this is also true for non-diasporic bodies). This scene gives form to the abject as an affective situation that blends confinement and an impulse out, a will to escape and an inability to do so (see Fig. 5.9). The dark walls on both sides of the door that spatially frame Sibel in the brightly lit bathroom visually parallel the action of the blood and the needle in the next scene, which both go out and stay in. Like her first suicide attempt, Cahit's suicide attempt, and Cahit driving his car into a wall, the abjection of the self results in being admitted to the hospital. The body needs to be 'straightened out' out of the path of the

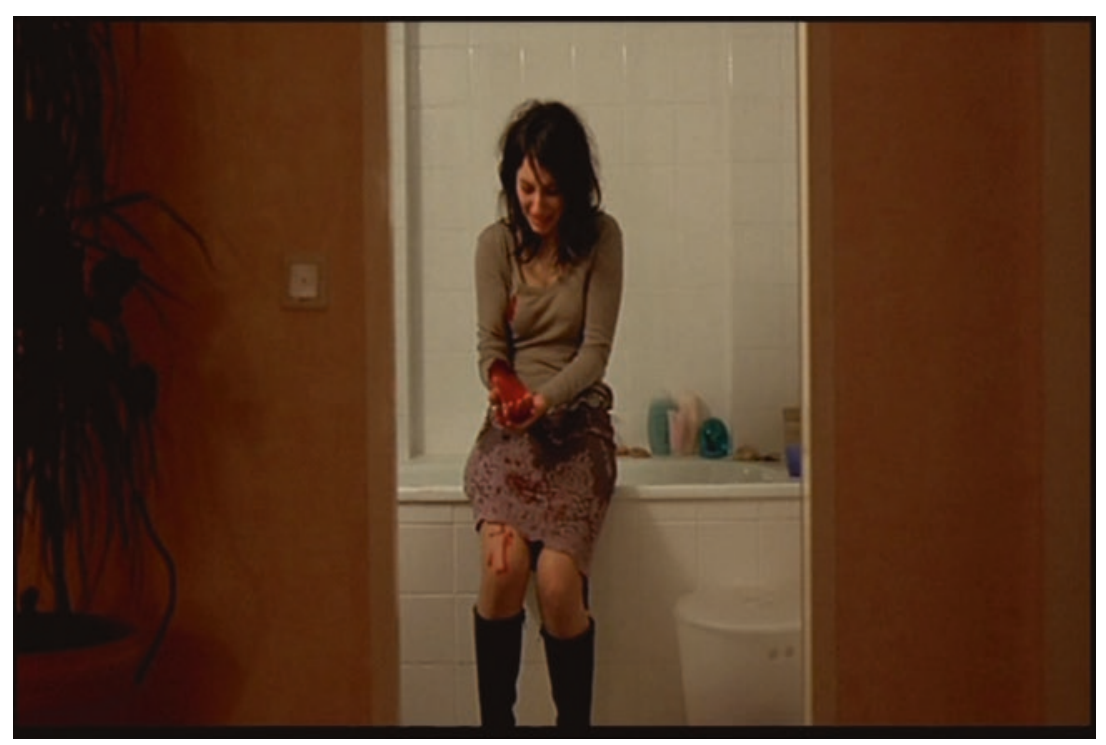

Fig. 5.9 Head-On: Sibel bleeding after cutting her veins open 
'melancholic migrant', be put back on the 'right path of happiness', and made 'docile', as Sara Ahmed would write $(2010,2014)$. One could interpret this scene as the medical institution (a symbol of the German state representing the socially acceptable) attempting to 'fix' Sibel, to bring her back to a socially acceptable state (one that is clean, proper, not opened up). However, looking at the forms of the sequence, following Brinkema's idea that affects have forms, gives us an insight into the affects of the film. The psychological scars of displacement, the inability to go home or find a home for oneself, take the form of physical scars.

Throughout the film, both Sibel's and Cahit's bodies are shown as the battleground of the uninhabitability of gender and race. Cahit is physically disciplined for killing Niko (he is sent to prison), and despite Sibel's occasional bouts of freedom, she is still constrained by patriarchal ideas that seek to control women's behaviour and mobility. After the incident, Sibel moves to Istanbul so her family cannot take revenge on her for bringing shame onto the family. If the first climax brought Cahit's mobility to a stop, the second climax of the film narratively and aesthetically arrests Sibel's mobility. After Sibel gets drunk (in the third dancing scene) and falls unconscious to the ground in the bar in Istanbul, the bartender rapes her as she lies face down on the floor in a medium-long shot. ${ }^{1}$ The frenetically moving camera and the Depeche Mode song that was playing become immobile and silent, respectively, which give shape to Sibel's arrested mobility and foreshadow the last part of the film when Sibel regains a domestic life. The abjection of Sibel's body, through the sperm of the bartender invading her body (and possibly getting her pregnant, although the biological origin of her daughter is not made clear in the film), continues in the following scene in which three men beat her up in the streets and leave her bleeding and unconscious. As she walks down the street after the bartender kicked her out of the bar, three men start shouting sexist comments at her: 'Hey baby! What are you doing out so late? Do you need a man?' These comments position her as an abnormal inhabitant of the so-called 'public' space, a space dominated and controlled by men. Although Sibel undoes binaries through her queering of gender, she is continually repositioned as female, in a body negatively affected by power-geometries. This scene in the streets of Istanbul gives form to the contradictions inherent in gender while it reinforces the body as necessarily gendered, a situation from which the subject can never fully escape following Butler. In addition to constantly changing her 'feminine' appearance in Hamburg and cross-dressing in Istanbul, the deep 
abjection of Sibel's body gives form to the uninhabitability of gender and to the body's habitation of space through affects and sensations. Rather than being a silent victim of the men's misogyny, Sibel shouts back and starts a physical fight with one of the men, who follows her. As the scene transmits the gendered aspects of mobility, it engenders a political statement, echoing social movements such as 'Take Back the Night'. Sibel's wilfulness is manifest on screen through her full habitation of cinematic spaces. Ahmed also describes the rebellious and disobedient character of those subjects who experience wilfulness: 'willfulness involves persistence in the face of having been brought down ... [and] persistence can be an act of disobedience' $(2014,2)$. With her face dripping in blood and angrily smiling, Sibel provocatively shouts to the men to beat her up even more, in a gesture of self-abjection (Fig. 5.10). The visual abjection of the self, by bringing out what should be in (her blood), gives form to the destruction of the subject as codified and ordered. As Sibel stands in the street, getting up in spite of having been brought down, she wilfully inhabits the space on screen and the diegetic space (the street). Her embodiment of a punk lifestyle manifests all the more clearly in her

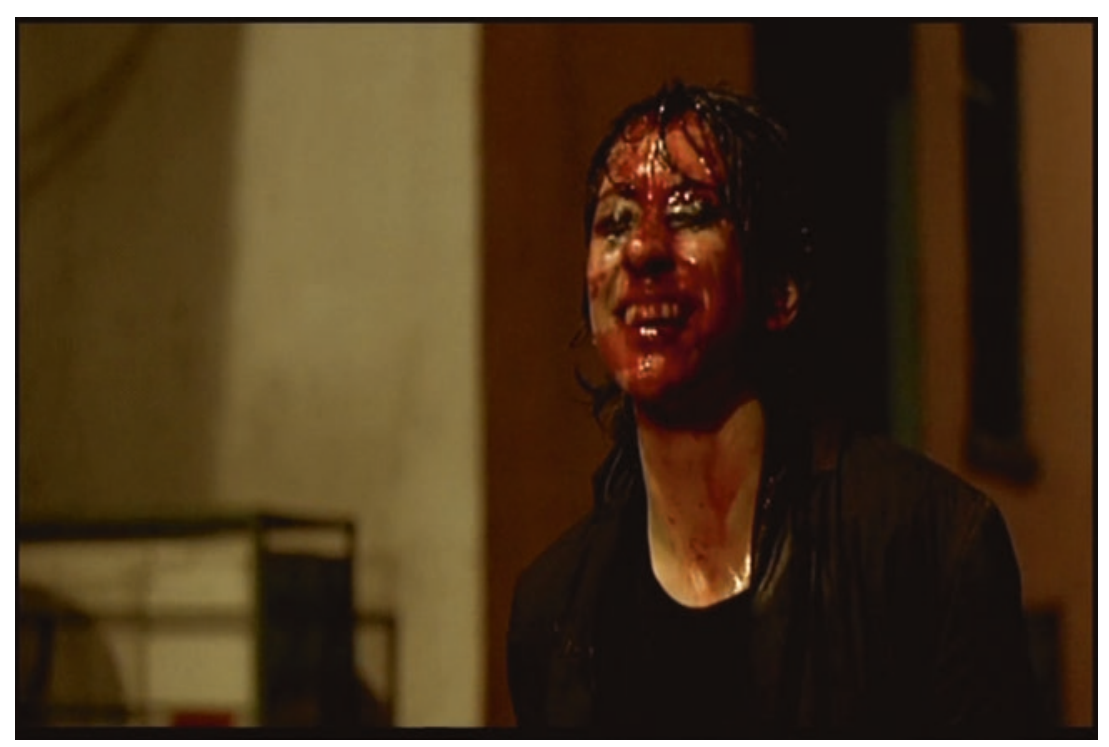

Fig. 5.10 Head-On: Sibel in a gesture of abjection 
nighttime habitation of Istanbul, by which she embraces a subculture that is in opposition to the neoliberal way of life that she attributes to her cousin Selma. While the diegesis of the film eventually expresses the inability to belong to 'public' space as a woman and an intercultural subject, the aesthetic of the film gives form to abjection as an affective and affirmative resistance to displacement. Similarly to the 'Black Lives Matter' movement, this resistance becomes what remains and leaves traces within and in spite of sociocultural codes, just as blood and scars leave traces on the streets and the body. The abjection as affirmative restistance may once become what transforms the codes.

\section{Windows, Hotels, And a Space for Pausing}

In the last part of the film, Sibel inhabits spaces that appear to contain her, as opposed to the streets and nightclub that Sibel 'invaded' through her punk way of life. Her habitation of the domestic space resonates with the predicament faced by women in the road movie genre, as Chap. 2 has shown, who tend to be judged, killed, or taken back to the domestic sphere as a punishment for their transgression into a ('public') sphere where they do not belong. However, as we will see, Sibel's body has not been made completely docile, which becomes apparent through the construction of the cinematic space. While Sibel attempted to build a space for herself in the streets of Hamburg and Istanbul, the final scenes of the film show how home is not anchored in place, but rather in time and social relations. While Head-On does not belong to the road movie genre, it retains the protagonist's attempt to find home through mobility, or rather to find an alternative home-home as sense of belonging, a 'home [that] can be "anywhere and everywhere" (Robertson 1997, 271) - in contrast to the monotonous and family domesticity that home can represent. The domestic space becomes a space of transit, a space for pausing, a space for reflection, and a space for finding one's own self in spite of patriarchal capitalist structures.

The abjection of the body, as explored in the previous section, also figures as a reaction to an unwilling containment within the capitalist system and its disciplinary organisation of time and space. Both Cahit and Sibel embrace a punk lifestyle, one that refuses the concept of career, consumption, and production within the logics of capitalism. In contrast with the neo-feminist figures that Hilary Radner (2010) describes in her book, Sibel is not a woman protagonist who can or wants to 'have it all', but 
rather who wants to get rid of it all. After she has left Hamburg for Istanbul, Sibel repositions herself in order to (wil)fully inhabit the city, by crossdressing and adopting a structured, scheduled lifestyle for a period, which allows her to hide her wilfulness. If her cousin Selma associates socioeconomic success with discipline and willpower (as she proudly says to Sibel, 'You just need to believe in yourself'), Sibel's disciplined habitation of the city arises as a consequence of her loss of erotic power; the double standards regarding women's sexuality have negatively affected her.

While the aesthetic of the sequence when Sibel moves to Istanbul appears 'disciplined' in time and space (reflecting the disciplinary structuring of bodies and space that Foucault describes in Discipline and Punish [1975]), it also points to Sibel's persistent refusal to integrate capitalist norms. Sibel's temporal acquiescence to the capitalist system is evident in how frameswithin-the-frame divide the cinematic space and how repetitive scenes structure the rhythm of the sequence. Fragmented images give shape to Sibel's containment as a docile body, and both the sound of Sibel's alarm clock ringing at 5:00 in the morning and her nighttime walks dictate the division of time. When the camera shows Sibel vacuuming and changing bed sheets in long obstructed and divided shots-marking her movements as repetitive and her attitude as one who is obeying the rules of the jobthe bright window in the background creates a visual alternative to Sibel's present habitation of space: it manifests as a micro-instance of her wilfulness. Several times, Sibel looks out the window, with the city made visible by the shot's depth of field, indicating her desire to be part of it. Julianne Pidduck quotes Mikhail Bakhtin in her essay on windows and women's spaces in film when she suggests that windows appear as thresholds, as 'chronotopes of crises and breaks in life' (Mikhail Bakhtin as cited in Pidduck 1998,382 ). Windows and mirrors in the takeaway restaurant where Sibel asks where she can find drugs, and the sound of Sibel's alarm clock being suddenly replaced by Turkish Romani music when she turns it off, give form to 'cracks' in the division of space and time. These 'cracks' suggest a wilfulness that persists, which first leads to abjection (as seen in the previous section) and then to building a space of reflection, a room of one's own.

At the end of the film, after Sibel is discovered lying in blood in the street by a taxi driver, the narrative returns to Hamburg, where Cahit is released from prison. Soon after, he leaves for Istanbul with the aim of finding Sibel. When Sibel is informed that Cahit is in town, she secretly calls him, whispers over the phone, and then hangs up hastily. Multiple cross-fades indicate time passing before Sibel and Cahit finally meet again. The portrayal of Sibel here is very different from the first time we saw her; 
she has a daughter, wears glasses, does not look directly into the camera, and is dressed in a rather formal, non-sexy manner. As Sibel tells Selma that she is meeting Cahit and will not be coming back for the weekend, her raised chin, calm tone, and confident body posture as she looks straight ahead through the window indicate that she remains wilful (see Fig. 5.11).

If for male road questers, becoming new, empowered subjects means finding a new home on the road, women protagonists on identity quests find themselves in their wilful habitation of space. Rather than defining 'mobility' as the road travelled and possessed, a 'democratic right' of access to the public sphere ('a sphere of personal freedom, leisure, and freedom of movement' Habermas 1989 [1962], 129), Head-On shows us the limitations of freedom for both women and men (an essential part of Braidotti's affirmative politics). The affirmative critical thinking and activism of Head-On relies on the recognition that 'humanity does not stem out of freedom, but rather that freedom is extracted out of the awareness of our multiple limitations ... affirmation [being] about freedom from the burden of negativity, through the understanding of these limitations' (Braidotti 201 1, 269). At the end of film, Sibel appears less 'resistant', less

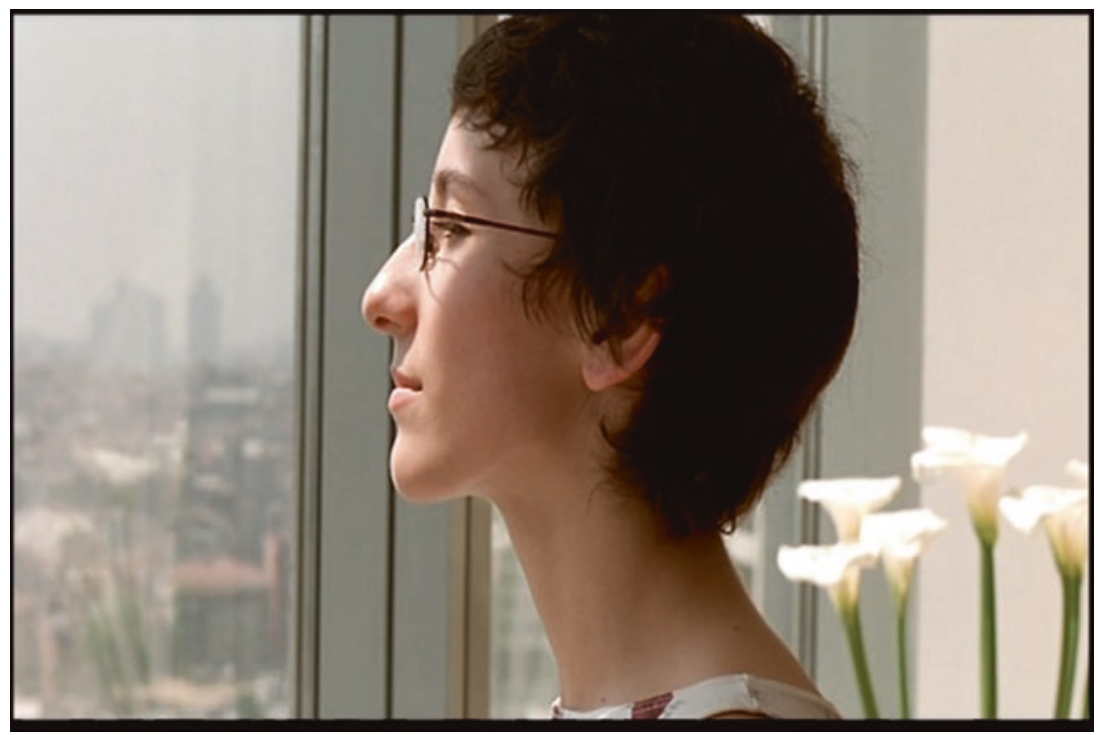

Fig. 5.11 Head-On: Sibel enjoying the sun on her face as she confidently looks over the city 
'against' in her wilfulness and habitation of space. She inhabits space more confidently and in a more peaceful and negotiated way than in her earlier iterations. Because the street could not provide Sibel with a home, windows now protect her from the world 'out there', a world that has continually threatened and violated her body, reminding her of her designated gender and position in society.

While the windows that separate Sibel from the city may indicate a retirement into the domestic sphere that is typical of women protagonists in road movies, they also give shape to a wilful desire to escape the exhaustion of having 'to insist on what is simply given to others' (Ahmed 2014, 149). As Ahmed explains about wilful subjects, 'a desire for a normal life does not necessary mean identification with norms' (149). Like the windows in Vendredi soir and the roof in Wadjda, the windows and balconies of Sibel's apartment and of the hotel room she shares with Cahit give form to a certain type of spatial power. While standing 'above' the city she sees without being seen, therefore escaping the male gaze that has threatened her in the past (and threatens Wadjda's and Laure's full habitation of social spaces). Likewise, Sibel's glasses act as mediators between herself and the urban space. Mary Ann Doane writes that women wearing glasses in films acquire an 'intellectual' appearance and become empowered as (female) spectators, gaining a right to look $(1990,50)$. Sibel's glasses function as a (cinematic) way to avoid sexist comments or as a barrier to those who might question the legitimacy of her presence in the street. Her ability to stop, be a spectator, look at the city from above or through the mediation of her glasses, figure as both acceptance of her limitations and her freedom to inhabit space, as a subject who pauses and reflects before acting and taking decisions, similarly to Jeanne and Marie in Messidor.

The windows of Sibel's apartment and the hotel room she shares with Cahit have replaced the windows of the hotel room that she was cleaning earlier in the film. Instead of embodying Sibel's desire to find a home the streets, windows have become mirrors of a space of belonging that she has found within herself. Sibel's contented smile and the light of the sun on her face that the window lets through give form to a peaceful inner space, a home (see Fig. 5.11). The bright lighting of this scene, her white flowery clothes, her subtle smile, and her proud body posture contrast with the dark and cloudy Istanbul of the previous sequence. Her glasses echo the double movement of 'taking in' the outside world and reflecting it, simultaneously welcoming its brightness and letting it bounce back out. Rather than a body inhabiting streets at night, hiding oneself behind dark makeup 
and dark clothes, Sibel has found a 'home' within herself, as the mise-enscène of this last sequence in Sibel's apartment and in the hotel room with Cahit suggests.

Just as social geographer Doreen Massey and film theorist Giuliana Bruno assert, home is always a space in transit, one that is constantly constructed and transformed through time and social relations. The hotel room in Istanbul where Sibel meets Cahit becomes a kind of home through the affective encounter of bodies. The mise-en-scène and cinematography of the scene show how home is located within affective exchanges and timely relations, rather than in a physical place. The sequence opens with a shot-reverse shot series of close-ups, positioning the characters' faces and naked shoulders in the middle of the frame. The close-ups, the warm light on the two bodies, and the micro-movements of both the camera and the characters give form to an intimate cinematic space, where time seems to stop and give place to desire. When Sibel and Cahit start touching, soft gasps and rustles rupture the silence, and the handheld camera filming them in close-up follows the slow movement of their faces kissing and hiding in each other's necks. The cinematography of this scene creates affects of belonging, a sort of home, and a room for their own selves where they are not abjected by being deemed 'other'.

The hotel allows a pause out of time, a pause for reflection, and an inquiry into the erotic. The hotel room acts as a sort of 'neutral' space, which encompasses numerous past and future stories (as seen in Chap. 3 on Vendredi soir); the absence of sounds from the city below also emphasise embodied micro-relations that temporarily suspend gendered powergeometries. In the following scene in which the characters have sex, two beds and a painting in between the beds symmetrically structure the fixed frame. It is a structure that Cahit and Sibel interrupt as they inhabit the space. As Cahit and Sibel's lovemaking breaks the symmetry of the image (see Fig. 5.12), the warm light on their naked bodies contrasts with the dark, cold colours of the room, which create an affirmative 'crack' in the setting of the diegetic space (the room) and in the socially structured reality. Sibel's introverted expression during the whole sequence-she either does not smile or only does so subtly - contrasts with her portrayal at the beginning of the film in Hamburg. The hotel room appears as a space in between inner and outer space, and as a space in transit between the domestic and the city, which the windows and balcony somehow join together. It gives Sibel a space to suspend, at least temporarily, power-geometries and her gendered situation as a mother and as a woman who lives through 'the 


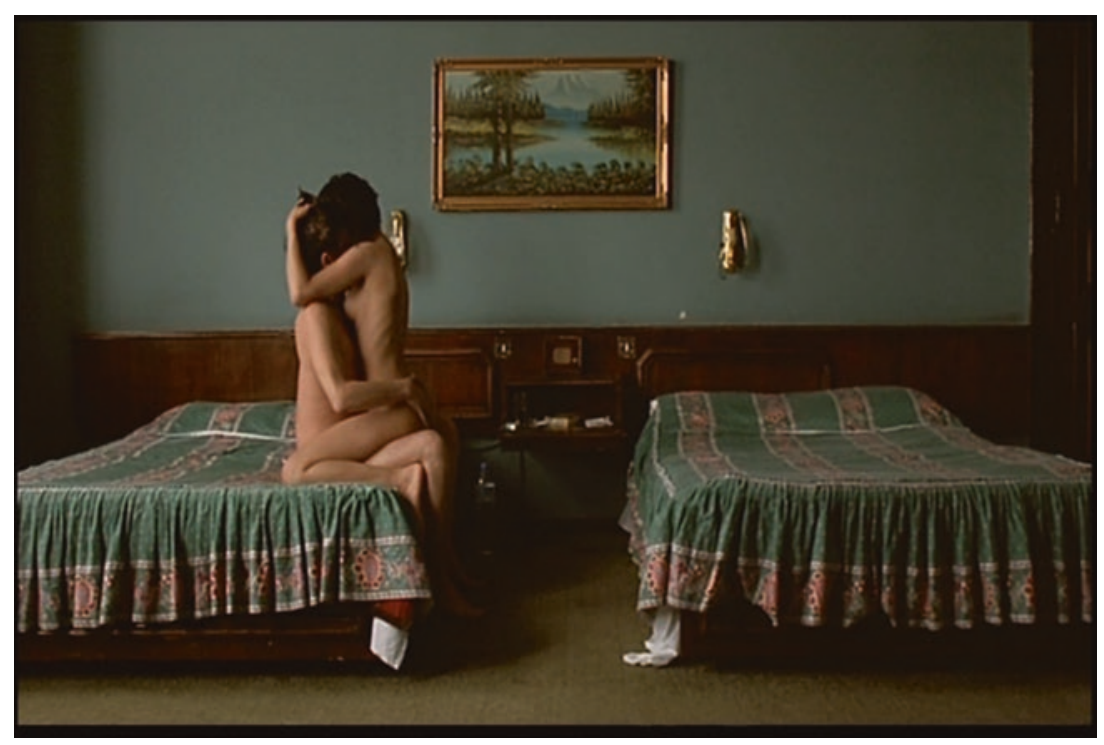

Fig. 5.12 Head-On: Sibel and Cahit making love and disturbing the spatial symmetry

accumulation of experiences of being silenced. At night, she is shown inside the hotel room with Cahit, looking at the city from the wide-open window, experiencing the air of the night on her naked skin, albeit protected and removed from the 'dangers' of the city (as the previous chapters also suggest regarding balconies). The rupture of the hotel room's symmetry, along with the warm tones of the characters' skin, suspend the neutrality of the room, make space, and create a sort of home. It becomes a space of wilfulness to not follow the prescribed path, a location to reconnect with the erotic, and an arena of belonging, which gives both characters a space to exist outside of their intercultural situation.

The sound of the scene also seems to create a pause, a place for reflection, and at once situates the protagonists in the present space-time and removes them from it. Asynchronous dialogue suddenly merges with their panting and rustling and progressively replaces the sounds of their lovemaking. Several pieces of asynchronous dialogue disrupt linear time and situate the characters in between present, past, and future space-times. When the city of Istanbul emerges in the previously dark and nearly silent room through a medium shot of the open window, the sounds of the 


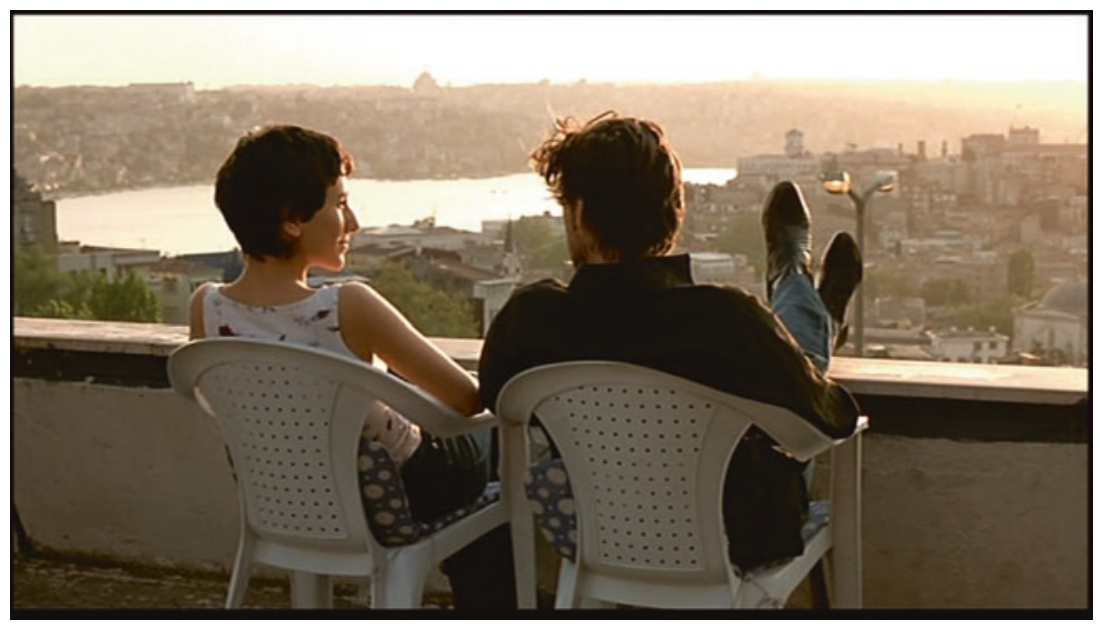

Fig. 5.13 Head-On: Sibel and Cahit looking at the city from above

evening adhan (an Islamic call for prayer) and the sight of the setting sun bring a concrete sense of time into the space. When the camera then films Sibel and Cahit as they sit on the balcony, looking at the city from above with their backs to the camera (see Fig. 5.13), Cahit's asychronous question to Sibel and her synchronous but post-synchronised response continues to disjunct the linear idea of space-time. The window and the balcony of the room produce thresholds in the space-time and mark a difference between the time outside the room and the characters' time, a space-time lived through affects. While the characters attempt to plan a possible future together, they live through a nostalgic image of the past. Their absence of physical contact with the exterior world, of which the balcony and the window offer a distanced viewpoint, signifies creating a space-time for themselves away from the present space-time and away from being characterised as 'other' or in-between-neither belonging to Germany nor to Turkey. This sequence is affirmative in the sense that it suspends a linear and fixed idea of time and space and presents space as always remaining in transit, in constant transformation through time and social relations. 


\section{Domestic Space and Gender Roles}

While the diegesis concentrates on the critique of the status quo and seems to conclude that women can neither freely inhabit public spaces nor aspire to freedom and independence, the aesthetic choices and musical tableaux of Head-On point to the continual transformation of space and power-geometries. When faced with the choice of staying at home with her partner and daughter at the end of the film, or following Cahit on the road to his hometown, Sibel decides to remain in Istanbul. This dilemma is actually an absence of choice, since in one instance she would remain in a stable domestic situation for her daughter's sake, and in the other instance, leaving with Cahit may mean entrapping herself in another heteronormative relationship. Going alone to Cahit's place of birth, Mersin, amounts to renouncing the life she has built in Istanbul and leaving behind her only remaining relative, her cousin Selma. There she might also have encountered similar kinds of spatial regulations to the ones she experiences with her current partner based on conventional heterosexual norms and expectations. As the film ends before this situation unfolds, and refuses to show Sibel's current partner, it does not visually cluster Sibel within the domestic sphere. Two bright establishing shots of Sibel in the street (one when she pushes her daughter's stoller, the other one when she walks, alone, to meet Cahit at the hotel) suggest that she is able to freely inhabit her environment, albeit within the limitations of her gendered situation.

Sibel's and Cahit's last appearances on screen give form to their sociocultural entrapment and to the limitations upon their freedom. The last scene with Sibel opens with a tight medium shot filmed by a handheld camera that follows her body movement as she packs her suitcase (presumably, with the intention to leave with Cahit). This brief shot then cuts to a fixed close-up of Sibel sitting on her bed in silence and with her head down. As music from a musical box and her partner's and daughter's joyful voices are heard, Sibel raises her head, only to lower it again slowly in the next shot, this time filmed in a fixed tight medium shot from behind (see Fig. 5.14). Sibel's plain grey t-shirt and its white rims echo the grey tone and thick white edges of the wardrobe in front of Sibel, the geometrical lines of which visually divide the image and enclose her body within multiple frames. The bareness of the mise-en-scène and Sibel's few movements within the fixed frame give shape to her resignation and limitation to her freedom, as a mother. Her body almost merges with the space. As Giuliana Bruno would put it regarding women's habitation of domestic spaces, the house is her dress expressing her own motions and emotions 


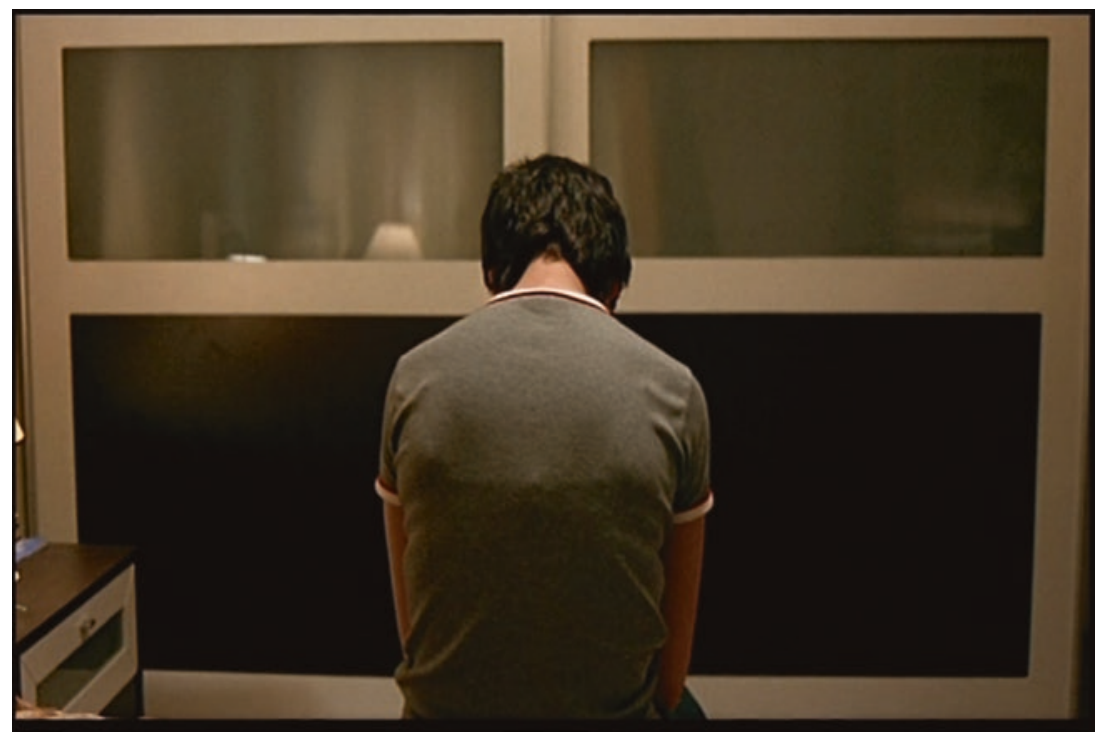

Fig. 5.14 Head-On: Sibel's limitation to freedom expressed through her habitation of cinematic spaces

(2002, 91-92). The cracks that Sibel's wilful body created on screen through eroticism, dance, and abjection seem to have closed down on her, only leaving the sound of the musical box as a hope for generational wilfulness.

The musical box creates a sound bridge that links Sibel's last scene to Cahit's and narratively expresses Sibel's decision to remain in Istanbul with her daughter and her partner. When Cahit last appears on screen, a close-up frames him alone inside a bus about to depart for his hometown of Mersin. As the bus reverses, the camera zooms out and pans slightly to keep the bus in the frame while filming Cahit from an increasing distance, contained by frames and behind windows. The cinematography sets a distance from the character, who is slowly leaving the frame of the shot. When Cahit's bus has left the frame, the camera keeps filming the passing traffic on the highway as another sound bridge featuring traditional Turkish music links the scene to the last tableaux of the film. While the woman singer kept silent during the three preceding tableaux-echoing, it seems, the institutionalised sexist punishment of Sibel for her possession of the erotic and her cross-dressing-her singing of the oral tale resumes in the final tableaux. 
The tableaux, along with the distancing cinematography of Cahit's last scene, take away the personal and places emphasis on the commonality of Sibel and Cahit's love story, and on the collective-human-limitation to freedom. As singing resumes in the final tableaux, it seems to introduce a wilful hope that a woman's voice can be heard in a world dominated by men. Head-On aesthetically introduces 'cracks' or lines of flight within the norms and expectations that its diegesis exposes. Despite uninhabitable subject identities that may appear inescapable, the hybrid, erotic and abject forms of the film's bodies affirmatively emphasise the possibility to conceive of subjects as deeply liminal. If mobility may not be the solution to transform oneself and one's environment, Messidor, Vendredi soir, Wadjda, and Head-On all show that the making and habitation of fluid spaces offer glimpses of hope and filmic ways to suspend the status quo.

\section{Note}

1. Sibel is not only punished for her queer appearance and moving around unchaperoned in public spaces, but also for drinking, which is not seen as acceptable for women, as film director Ulrike Ottinger also shows in Bildnis einer trinkerin/Ticket of no return.

\section{REFERENCES}

Ahmed, Sara. 2010. The Promise of Happiness. Durham/London: Duke University Press.

- 2014. Willful Subjects. Durham: Duke University Press.

Akin, Fatih. 2004. Gegen Die Wand [Head-On]. DVD. Germany/Turkey: Strand Releasing.

- 2007. Auf Der Anderen Seite [The Edge of Heaven]. DVD. Germany/ Turkey: Strand Releasing.

Appadurai, Arjun. 2002. The Right to Participate in the Work of the Imagination. In Transurbanism, ed. Joke Brouwer and Arjen Mulder. Rotterdam: NAi Publishers.

Barthes, Roland. 1980. La chambre claire: note sur la photographie. Paris: Gallimard. Braidotti, Rosi. 2011. The New Activism: A Plea for Affirmative Ethics. In Art and Activism in the Age of Globalization, ed. L. De Cauter, R. De Roo, and K. Vanhaesebrouk, 264-270. Rotterdam: NAi Publishers.

Bruno, Giuliana. 2002. Atlas of Emotion: Journeys in Art, Architecture, and Film. London/New York: Verso.

Butler, Judith. 1993. Critically Queer. GLQ: A Journal of Lesbian and Gay Studies l (1): 17-32. 
de Certeau, Michel. 1984. The Practice of Everyday Life. Berkeley: University of California Press.

Deleuze, Gilles, and Félix Guattari. 1980. Capitalisme et Schizophrenie: Mille Plateaux. Paris: Editions de minuit.

Di Méo, Guy. 2011. Les murs invisibles: femmes, genre et géographie sociale. Paris: Armand Colin.

Doane, Mary Ann. 1990 [1982]. Film and the Masquerade: Theorizing the Female Spectator. In Issues in Feminist Film Criticism, 41-57. Bloomington/ Indianapolis: Indiana University Press.

Dyer, Richard. 2002 [1992]. Only Entertainment. London/New York: Routledge. Eleftheriotis, Dimitris. 2012. Cinematic Journeys: Film and Movement. Edinburgh: Edinburgh University Press.

Foucault, Michel. 1975. Surveiller et punir: naissance de la prison. Paris: Gallimard. Grosz, Elizabeth. 1994. Volatile Bodies: Toward a Corporeal Feminism. Bloomington/Indianapolis: Indiana University Press.

- 2010. Feminism, Materialism, and Freedom. In New Materialisms: Ontology, Agency, and Politics, ed. Diana Coole and Samantha Frost, 139-157. Durham: Duke University Press.

Habermas, Jürgen. 1989 [1962]. The Structural Transformation of the Public Sphere: An Inquiry into a Category of Bourgeois Society. Malden: Polity Press.

Hall, Stuart. 1990. Cultural Identity and Diaspora. In Identity: Community, Culture, Difference, ed. Jonathan Rutherford. London: Lawrence \& Wishart.

Kristeva, Julia. 1980. Pouvoir de l'horreur: Essai sur l'abjection. Paris: Point.

Kübler-Ross, Elisabeth, and David Kessler. 2005. On Grief and Grieving: Finding the Meaning of Grief through the Five Stages of Loss. New York: Scribner.

Lefebvre, Henri. 1974. La production de l'espace. Paris: Anthropos.

Lorde, Audre. 1984. Sister Outsider: Essays and Speeches. Berkeley: Crossing Press.

Massey, Doreen B. 1994. Space, Place, and Gender. Minneapolis: University of Minnesota Press.

McDowell, Linda. 1999. Gender, Identity and Place: Understanding Feminist Geographies. Minneapolis: University of Minnesota Press.

McRobbie, Angela. 1990. Feminism and Youth Culture: From 'Jackie' to 'Just Seventeen'. Hampshire: Macmillan International Higher Education.

Muñoz, José Esteban. 2009. Cruising Utopia: The Then and There of Queer Futurity. New York: New York University Press.

Naficy, Hamid. 2001. An Accented Cinema: Exilic and Diasporic Filmmaking. Princeton: Princeton University Press.

Ottinger, Ulrike. 2008 [1979]. Bildnis Einer Trinkerin. Aller Jamais Retour. DVD. West Germany: Women Make Movies.

Pidduck, Julianne. 1998. Of Windows and Country Walks: Frames of Space and Movement in 1990s Austen Adaptations. Screen 39 (4): 381-400.

Pollock, Griselda. 1988. Vision and Difference: Femininity, Feminism, and Histories of Art. London/New York: Routledge. 
Radner, Hilary. 2010. Neo-Feminist Cinema: Girly Films, Chick Flicks, and Consumer Culture. New York: Routledge.

Rieker, Martine, and Kamran Asdar Ali, eds. 2008. Gendering Urban Space in the Middle East, South Asia, and Africa. New York: Palgrave Macmillan.

Robertson, Pamela. 1997. Home and Away: Friends with Dorothy on the Road in Oz. In The Road Movie Book, ed. S. Cohan and I.R. Hark, 271-286. London: Routledge.

Rose, G. 1993. Feminism and Geography: The Limits of Geographical Knowledge. Cambridge: Polity Press.

Siegel, Kristi. 2004. Intersections: Women's Travel and Theory. In Gender, Genre, and Identity in Women's Travel Writing, ed. Kristi Siegel, 1-14. New York: Peter Lang.

Siewert, Senta. 2008. Soundtracks of Double Occupancy: Sampling Sounds and Cultures in Fatih Akin's Head On. In Mind the Screen: Media Concepts According to Thomas Elsaesser, ed. Patricia Pisters Jaap Kooijman and Wanda Strauven, 198-208. Amsterdam: Amsterdam University Press.

Solnit, Rebecca. 2001. Wanderlust: A History of Walking. London: Penguin Books. Spain, Daphne. 1992. Gendered Spaces. Chapel Hill: University of North Carolina Press.

Wilson, Elizabeth. 1991. The Sphinx in the City: Urban Life, the Control of Disorder, and Women. Berkeley: University of California Press.

- 2001. The Contradictions of Culture: Cities, Culture, Women. London: SAGE Publications.

Open Access This chapter is licensed under the terms of the Creative Commons Attribution 4.0 International License (http://creativecommons.org/licenses/ by $/ 4.0 /$ ), which permits use, sharing, adaptation, distribution and reproduction in any medium or format, as long as you give appropriate credit to the original author(s) and the source, provide a link to the Creative Commons licence and indicate if changes were made.

The images or other third party material in this chapter are included in the chapter's Creative Commons license, unless indicated otherwise in a credit line to the material. If material is not included in the chapter's Creative Commons licence and your intended use is not permitted by statutory regulation or exceeds the permitted use, you will need to obtain permission directly from the copyright holder.

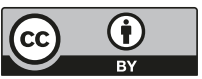

